Article

\title{
Research on Power Demand Suppression Based on Charging Optimization and BESS Configuration for Fast-Charging Stations in Beijing
}

\author{
Yian Yan ${ }^{1, *}$, Jiuchun Jiang ${ }^{1}$, Weige Zhang ${ }^{1}$, Mei Huang ${ }^{1}$, Qiang Chen ${ }^{2}$ and Huang Wang ${ }^{1}$ \\ 1 School of Electrical Engineering, Beijing Jiaotong University, No. 3 Shang Yuan Cun, Haidian District, \\ Beijing 100044, China; jcjiang@bjtu.edu.cn (J.J.); wgzhang@bjtu.edu.cn (W.Z.); mhuang@bjtu.edu.cn (M.H.); \\ 15121475@bjtu.edu.cn (H.W.) \\ 2 Beijing Huashang Sanyou New Energy Technology Co. Ltd., No. 9 Chuangyi East Road, East District, \\ Economic Development Zone, Tongzhou District, Beijing 100100, China; 13501018889@163.com \\ * Correspondence: yanyian@bjtu.edu.cn; Tel.: +86-10-5168-4056; Fax: +86-10-5168-3907
}

Received: 30 June 2018; Accepted: 19 July 2018; Published: 24 July 2018

Featured Application: The proposed strategy is aimed to solve the peak charging power demand issue of pure electric bus fast-charging station. It is effective for the charging power suppression of stations in the area with extremely limited distribution capacity.

\begin{abstract}
In order to reduce the recharging time of electric vehicles, the charging power and voltage are becoming higher, which has led to a huge distribution capacity demand and load fluctuation, especially in pure electric buses (PEBs) with large onboard batteries. Based on one actual direct current (DC) fast-charging station, a two-step strategy for the suppression of the peak charging power was developed in this paper, which combined charging optimization and a battery energy storage system (BESS) configuration. A novel charging strategy was proposed, with the PEBs fast-charging during operating hours and normal charging at night, based on a new charging topology. Then, a charging sequence optimization model was established, according to the operation characteristics analysis of the DC fast-charging station. The particle swarm optimization (PSO) algorithm is applied to optimize the charging sequence, which is disordered at present. Linear programming is used to configure the battery energy storage system in order to further decrease the peak charging power and satisfy the distribution capacity constraint. The two-step strategy was simulated by the dataset from the real station. The results show that the distribution capacity demand, charging load fluctuation, electricity cost, and size of the BESS were significantly decreased.
\end{abstract}

Keywords: pure electric buses; sequence optimization; charging topology; BESS

\section{Introduction}

Electric vehicles (EVs) have been presented as a promising solution for reducing fossil fuel consumption and air pollution worldwide [1-4]. The market penetration of EVs has rapidly increased in populated cities in recent years. In Beijing, China, the government has strongly pushed the application and development of pure electric vehicles to lessen the impact of vehicle exhaust emissions on air quality. The program states that more than 30,000 fossil fuel public buses will be completely replaced by zero-emission pure electric buses (PEBs), and an appropriate number of fast-charging stations will be built for the PEBs' recharging.

As for the developing trends, the EVs' charging power and voltage should be higher, so as to reduce the recharging time and to allow the owners to obtain the benefits of low electricity, compared to conventional internal combustion engine vehicles [5]. Based on the rapid development of 
charging technologies, high power direct current (DC) fast-charging has become available and popular. Compared with normal alternating current (AC) charging and battery-swapping charging, it has a shorter recharging duration and lower investment for different types of spare battery packs [6,7].

Depending on the battery and vehicle type, a recharge range of greater than $100 \mathrm{~km}$ in less than $10 \mathrm{~min}$ is easily achievable in fast-charging mode [8]. Compared with the private EVs, the PEB has its own characteristics, namely, a larger onboard battery capacity, operation according to the route schedule, and charging according to the driver's will at a fixed station within limited intervals. All of these factors bring a new challenge, that is, that the distribution capacity demand and the charging load fluctuation will be higher [9].

However, the current distribution capacity only considers the traditional load in the design process, so the extra megawatt level distribution capacity demand of fast-charging station construction cannot be satisfied. As the onboard battery is more than $120 \mathrm{kWh}$ and the charging duration is less than $15 \mathrm{~min}$, the fast-charging power of one PEB is high, up to $230 \mathrm{~kW}$. Thus, the cost of the expansion of the power grid capacity is nearly 10,000 Chinese Yuan per kVA (CNY/ kVA) in Beijing. The construction locations of the charging stations will be limited in some areas where they are necessary. Furthermore, there is a large industrial electricity tariff standard that is applied to fast-charging stations in Beijing and other cities in China, where a $32 \mathrm{CNY} / \mathrm{kVA}$ (4.8421 USD/kVA) per month basic capacity price (BEP) is charged according to the capacity of the distribution transformer, in addition to the time-of-use (TOU) electricity cost. For this, the operation cost may be further increased in the stations with a large distribution capacity. So, the suppression of the peak charging power is a critical issue for the design and operation of PEB fast-charging stations.

In the existing literature, the charging optimization of electric vehicles (EVs) has been widely researched. The authors of [10] proposed a charging schedule planning method based on an actual electric bus system, which effectively reduced the electricity cost with three-level TOU tariffs. While the scenario was one bus line, ten electric buses, and a charging power at $50 \mathrm{~kW}$, the cost of the distribution capacity was not considered. An optimal charging strategy to minimize the demand charges was presented based on the simulation of charging and running an electric bus (EB) fleet. Research into charging thresholds and charging schedules have developed, and the electricity cost comparison and economic fleet size have been given in [11]. However, the charging schedule used for the EBs operating in a route with one $500 \mathrm{~kW}$ catenary arm fast charger was not suitable for an integrated fast-charging station with several routes and charging piles. The authors of [12] minimized the electricity purchase costs of the aggregators by scheduling the charging loads of plug-in electric vehicles (PEVs) with normal charging at home, and the charging power was at the level of several $\mathrm{kW}$. An energy management scheme for an off-board EV smart charger was proposed in order to support the grid against disturbances, for the application of vehicle-to-grid (V2G) or grid-to-vehicle (G2V) in [13]. A general model was proposed for the charging/discharging control of EVs in the procedure of vehicle-to-anything (V2A) in [14]. V2G technology can support the power demand of the grid, and the peak power of the station can be reduced by vehicle-to-vehicle (V2V). Reference [15] proposed an optimal decentralized protocol for electric vehicle charging using valley-filling, which contained an optimal decentralized charging algorithm, asynchronous optimal decentralized charging algorithm, and a real-time optimal decentralized charging algorithm. However, it is only suitable for private EVs charging at night, as the charging control of PEBs running without interruption cannot apply that protocol.

A coordinated charging strategy for electric taxis in a temporal and spatial domain was presented in [16], where the PSO algorithm was used to balance the charging load distribution at different stations, as well as the times for the electric taxis. The authors in [17] proposed two real-time coordinated charging strategies to improve the charging costs of an electric bus fast-charging station responding to the time-of-use electricity prices. However, the research and simulation only considered five electric buses on one route, so the simulated bus operation and charging power could not accurately represent the conditions of actual PEB fast-charging stations. The authors of [18] proposed a novel decentralized 
valley-filling charging strategy, where a day-ahead pricing scheme that varied in both time and power forms was designed by solving a minimum-cost optimization problem at a device-level. A DC bus concept is proposed and validated for PEVs in [19], where the charging topology was established with a bipolar DC bus, based on a central neutral-point clamped (NPC) converter. This provided flexibility to the connection of the loads and electrical storage systems (ESSs), and had higher voltage and power handling capabilities.

As is well known, the alternative locations of charging stations are limited by the bus lines. If the distribution capacity is extremely limited, the charging power demand needs to be further decreased [20]. The battery energy storage system (BESS) is widely used to shave the peak power in many scenarios. The BESS was used as a buffer to reduce the charging load fluctuation and to shave peak power [21]. The authors in [22] applied electrical storage systems as a way to reduce the operational costs of the station and to alleviate the negative impacts of the station operation on the power grid in the fast-charging stations of the PHEVs. Through the load prediction of the PHEVs, the size of the ESSs of many different types of energy storage were compared. However, the comprehensive revenue of the BESS may be less than the investment, because the peak charging power of the station was usually up to a megawatt level and the total charging electricity was only several kilo $\mathrm{kWh}$. The research has focused on the charging optimization of private EVs or taxis, using the probability method to describe the charging characteristic based on the gasoline vehicle data. The main methods are as follows.

(1) Using the charging price incentive mechanism to guide the charging behaviors of EV, owners can reduce the electricity cost, and the charging power is reduced during the peak duration of the distribution network.

(2) Control the charging power through valley-filling to reduce the impact on the basic distribution load, and the total charging load level is less than hundreds of kilowatts.

(3) Reduce the charging load fluctuation by configuring the energy storage system, considering the size of the ESS and the profit by using time-of-use tariffs, and the cycle lifetime of BESS is rarely considered.

A few studies have been performed over the electric bus and fast-charging, while the optimization objective is usually one route with several buses. The configuration of the station seriously affects the operation of the bus fleet and charging optimization. The BESS is usually used to directly regulate the charging power without charging optimization. There have been few studies on the issue of distribution capacity suppression at fast-charging stations in megawatts level.

This work aims at reducing the peak charging power of the PEB fast-charging station in Beijing. The characteristics of configuration and operation of the PEB fast-charging station are presented through the analysis of actual data. A two-step strategy is presented; first, decreasing the peak charging power by the charging mode optimization in the operating hours and at night, and second, further reducing the power by the configuration of BESS. In the charging mode optimization, the charging sequence optimization model in the operating hours is established, therefore, the particle swarm optimization (PSO) algorithm was applied to find the optimal solutions. Thus, a new charging topology concept was recommended, where it was easy for the high power and voltage fast-charging station to change the number of charging piles. In order to further decrease the peak charging power, the BESS was used to shift the charging power according to the TOU tariffs, and to reduce the total cycle lifetime cost of the battery. A linear programing algorithm is used to accomplish the optimization.

The results of the charging optimization case showed that the power requirement could be reduced by $43.06 \%$. The cases of BESS configuration with the original and optimized charging load were developed, and the results indicated that the two-step strategy could significantly restrain the power demand by up to $56.67 \%$, which could make maximum profits at the same time.

The rest of this paper is organized as follows. The configuration and operation of the typical DC PEB fast-charging station is presented in Section 2. In Section 3, the new charging topology is 
shown and the proposed charging optimization model is developed. The BESS configuration method considered the battery cycle lifetime and the simulation results are detailed in Section 4 . The case study and result analysis are carried out in Section 5. Finally, the conclusions are given in Section 6.

\section{Operation of the Fast-Charging Station}

The operation of the station and the PEB fleet are mainly influenced by the station configuration and the type of PEBs. The charging topology will decide the charging service ability. The peak charging power is related to the rate charging power and behaviors of the PEBs. For a short charging duration, the fast-charging mode is widely utilized by the operators, instead of purchasing extra PEBs to satisfy the operation demand. This paper focused on one typical DC fast-charging station, used currently in Beijing, to analyze and research.

\subsection{Fast-Charging Station Configuration}

This station has operated for more than one year, where the designed distribution capacity is $4 \mathrm{MW}$. There are eight fast-charging sticks of $750 \mathrm{~V}$ and $450 \mathrm{~kW}$ that were constructed in separate charging lines (each charging line contains the respective energy conversion equipment). It can serve five bus routes with 45 PEBs. The charging system topology is shown in Figure 1. The fast-charging station charging system connects to the $10 \mathrm{kV}$ distribution network and the eight charging lines are all the same. Each line contains one transformer, one AC/DC module, one charging stick (with electricity measurement apparatus), and some power cables.

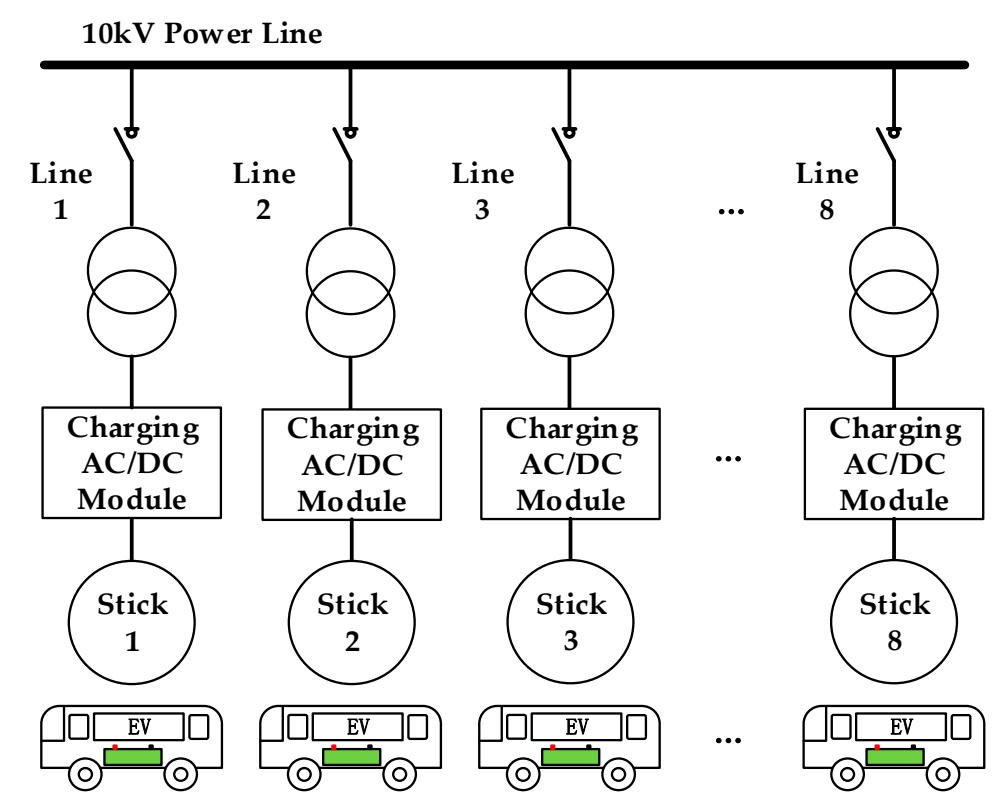

Figure 1. Charging topology of the direct current (DC) fast-charging station.

The PEBs of the fleet were made by the Beiqi Foton Motor Co. Ltd. (Beijing, China), the rated energy of the onboard lithium battery pack was $119.62 \mathrm{kWh}$, and the nominal voltage was 553.8. The maximum charging power was two times that of the rated onboard energy. The detailed information of the vehicle is shown below in Table 1. 
Table 1. Pure electric bus parameters.

\begin{tabular}{cc}
\hline Parameter & Value \\
\hline Vehicle Brand & Foton \\
Vehicle Type & BJ612EVCA-19 \\
Total Weight $(\mathrm{kg})$ & $18,000.00$ \\
Shape $(\mathrm{L} \times \mathrm{W} \times \mathrm{H})(\mathrm{mm})$ & $12,000 \times 2550 \times 3100$ \\
Battery Voltage $(\mathrm{V})$ & 553.80 \\
Battery Capacity $(\mathrm{Ah})$ & 216.00 \\
Electric Quantity $(\mathrm{kWh})$ & 119.62 \\
\hline
\end{tabular}

\subsection{Station Operation}

The researched DC PEB fast-charging station served two loop lines, H55 and H56, and three other lines operated in the origin-terminal mode, lines 863,864 , and 869 . The details of the PEB lines are shown in Table 2.

Table 2. The operation details for each line.

\begin{tabular}{ccccc}
\hline Line No. & Num. & $\begin{array}{c}\text { Distance } \\
(\mathbf{k m})\end{array}$ & $\begin{array}{c}\text { Time } \\
\text { (minutes) }\end{array}$ & $\begin{array}{c}\text { Loops before } \\
\text { Charging }\end{array}$ \\
\hline H55 & 5 & 9 & 30 & 3 or 4 \\
H56 & 5 & 12 & 30 & 3 or 4 \\
863 & 14 & 54 & 120 & 2 \\
864 & 7 & 18 & 35 & 2 \\
869 & 14 & 44 & 120 & 2 \\
\hline
\end{tabular}

For the constant operation rules of the bus lines, the charging load is similar day by day from the recorded charging data in the same season. This paper selected the data of a normal working day to analyze the charging load characteristics. Because of the shortage of measurements at the station, we obtained the total charging power based only on the recorded charging duration and electricity quantity. Through the charging power accumulation of each PEB, the charging load is shown in Figure 2 in the unit of minutes.

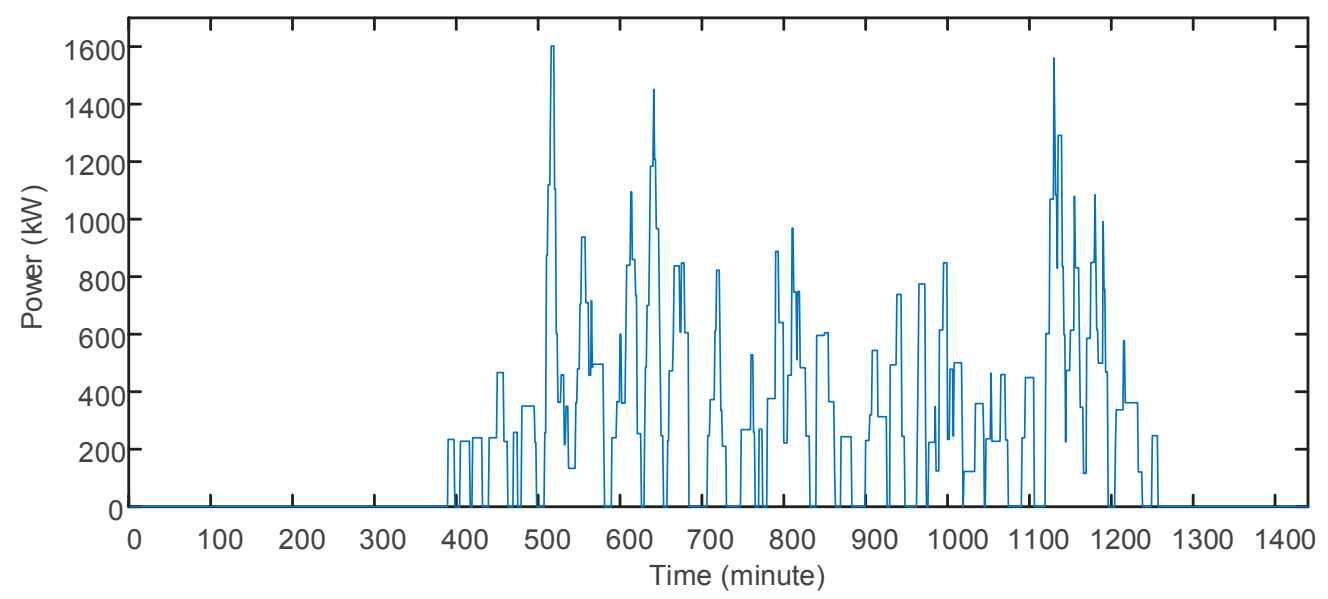

Figure 2. Total charging load of the station.

Although a great number of charging stations have been designed and deployed in different cities in China in recent years, most stations are designed and constructed according to the slow charging mode or fast-swapping mode. For insufficient design experience on a fast-charging station, the design on the distribution capacity and the quantity of charging sticks is based only on the existing rules 
and considers the extreme charging conditions. Furthermore, all of the PEBs are charged randomly according to the driver's will. Therefore, the peak charging power is huge and the charging load fluctuation is serious. The load curve is shown in Figure 2. The peak charging power was $1601.7 \mathrm{~kW}$ and the average charging power was only $284.93 \mathrm{~kW}$. The load rate was $17.79 \%$ and the total quantity of the charging electricity was $5128.8 \mathrm{kWh}$ in one day. The operation duration of the station was $16 \mathrm{~h}$, from 6:00 a.m. to 10:00 p.m. Compared with the station configuration and distribution capacity, the real demands of the charging power and facilities were not as high as the designed estimation. The charging station was not well used, which is a huge waste of capital investment and distribution resources.

\subsection{Characteristics of the PEB Fleet}

The average electricity cost is important for the optimization threshold judgment of PEBs, and is based on the monthly data of the operating mileage and energy consumption, which can be approximately calculated. Through the buses setting off schedule and the lines' distance [23], this paper calculated the energy cost of each line based on the actual operation data of October, in 2016. Using line $\mathrm{H} 55$ as an example, the on-board battery electricity was $119.62 \mathrm{kWh}$, the length of a single loop was $9 \mathrm{~km}$, the total charging electricity was $13,815 \mathrm{kWh}$, and the whole day running distance was $522 \mathrm{~km}$. Using Equation (1), the PEB energy consumption per kilometer was calculated as $0.854 \mathrm{kWh} / \mathrm{km}$. The energy consumption of each line is shown in Table 3.

$$
E_{\mathrm{Cos} \_ \text {H55 }}=\frac{E_{\text {month_H55 }}}{D_{\text {month }} \times S_{H 55}}
$$

where $E_{\text {cost_H55 }}$ is the energy cost of line $\mathrm{H} 55$ in $\mathrm{kWh} / \mathrm{km} ; E_{\text {month_H55 }}$ is the whole charging electricity in October; $D_{\text {month }}$ is the days of month; and $S_{H 55}$ is the whole running distance of line H55 in one day.

Table 3. The energy consumption of each line.

\begin{tabular}{ccccc}
\hline Line No. & Electricity (kWh) & Days of Month (d) & $\begin{array}{c}\text { Distance Per Day } \\
\mathbf{( k m )}\end{array}$ & $\begin{array}{c}\text { Energy Cost } \\
\mathbf{( k W h} / \mathbf{k m})\end{array}$ \\
\hline H55 & $13,815.6$ & 31 & 522 & 0.854 \\
H56 & $15,985.6$ & 31 & 600 & 0.859 \\
863 & $51,936.8$ & 31 & 1890 & 0.886 \\
864 & $27,579.2$ & 31 & 928 & 0.959 \\
869 & $48,184.6$ & 31 & 1628 & 0.955 \\
Total/Ave. & $157,501.8$ & 31 & 5568 & 0.912 \\
\hline
\end{tabular}

Based on the same data from October 2016, the statistical distribution analysis of the returned PEBs of the state of charge (SOC) was analyzed. As shown in Figure 3, the SOCs of the returned PEBs were mostly above $50 \%$. Thus, the maximum rate was $95.98 \%$ and the minimum rate was $79.28 \%$, the rates of the buses over $60 \%$ SOC were $73.37 \%$ and $46.63 \%$ at the maximum and minimum, respectively. The safety SOC threshold of the on-board battery for the bus running back to the charging station was $30 \%$. Because of the underutilization of the on-board battery and drivers' random charging, the total charging number and frequency were higher than necessary. This led to huge peak charging power and load fluctuation. 


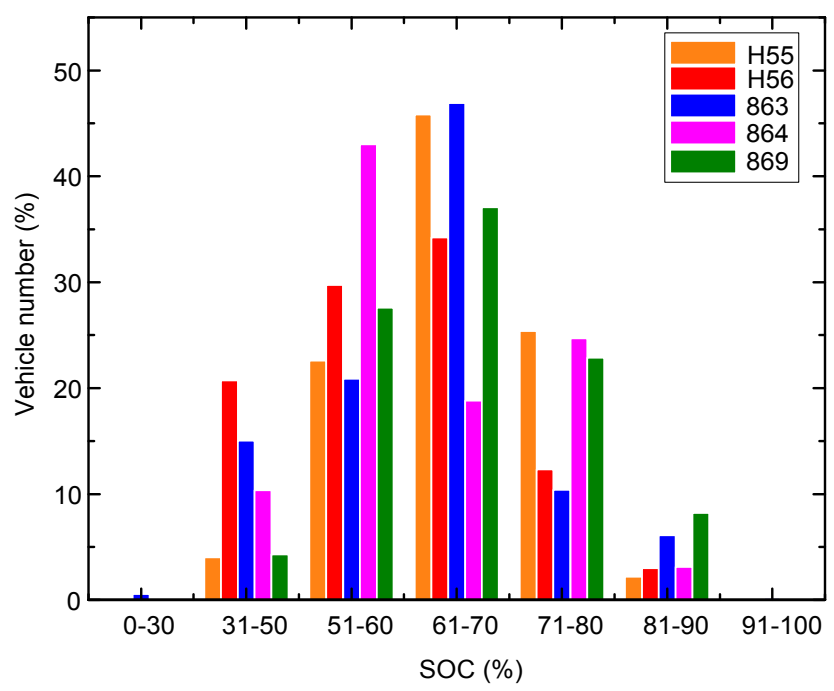

Figure 3. State of charge (SOC) distribution of the returned pure electric buses (PEBs).

According to the analysis of the station operation characteristics, the onboard battery can support the buses running more loops on different lines above the safety battery electricity threshold. At present, the drivers charge very frequently because of the range anxiety, which leads to a high charging frequency and charging load congestion. This paper proposes a strategy of fast-charging during operating hours and normal charging at night, in order to decrease the peak charging power. In order to conveniently shift the DC charging power and adjust the change of charging ports, a new charging topology is needed.

\section{Operation Optimization}

According to the charging load, the highest charging power occurs when several buses charge at the same time. Each PEB on different routes has its own operation schedule. If the SOC of the returned PEB is sufficient for the next loop, charging can be arranged in a suitable interval, which is related to the route distance, on-board battery capacity, and electricity consumption per $\mathrm{km}$. This section will analyze the operation of the PEBs and develop the charging optimization strategy for a PEB fast-charging station. Some symbols used in the operation optimization are shown in Table 4.

Table 4. List of some symbols used in the operation optimization.

\begin{tabular}{cc}
\hline Symbol & Explanation \\
\hline$V_{i, s}^{k}$ & Charging start time of PEB $k$ on the $i$ th returning to the station \\
$V_{i, e}^{k}$ & Charging end time of PEB $k$ on the $i$ th returning to the station \\
$\mathrm{N}_{B}^{k}$ & Number of PEB $k$ returning to the station without the last trip \\
$d_{i}^{k}$ & Charging or not of PEB $k(1$ or 0$)$ \\
$t_{i}^{k}$ & Charging duration related to $d_{i}^{k}$ \\
$E_{i}^{k}$ & Charging energy of PEB $k$ on $i$ th returning to the station \\
$E_{0}^{k}$ & Full energy state of PEB $k$ \\
$p_{c h}$ & Nominal charging power of the stick \\
$\mathrm{N}_{\text {stick }}$ & Quantity of sticks of the station \\
$C_{E_{-} \text {total }}$ & Total cost of electricity $(\mathrm{CNY})$ \\
$c_{\text {ele }}$ & Time-of-use tariffs \\
$\Delta t$ & Time interval \\
\hline
\end{tabular}




\subsection{The Proposed New Charging Topology}

As shown in Figure 4, the proposed new topology uses power diodes and DC/DC modules to build a bipolar DC bus on $690 \mathrm{~V}$. It contains more DC/DC charging modules to achieve the charging strategy, namely fast-charging during operating hours and normal charging at night. For the modularization of the transformer and converters, it is easy for the capacity extension or reduction of PEB fast-charging stations. This topology uses a low turns-ratio transformer to increase the secondary side voltage of the transformer to AC $690 \mathrm{~V}$. As the DC charging voltage of PEB is over $600 \mathrm{~V}$, it can reduce the AC/DC voltage deviation in the low-voltage side. As is well known, the diode rectifiers have a higher conversion efficiency and lower price than the pulse width modulation (PWM) modules, and the three-level DC/DC modules also have a high conversion efficiency. For the new station design, the new topology can reduce the quantities of transformers and converters. Furthermore, it can decrease the energy conversion losses during the charging procedure. The station charging efficiency is increased with the construction investment reduction at the same time.

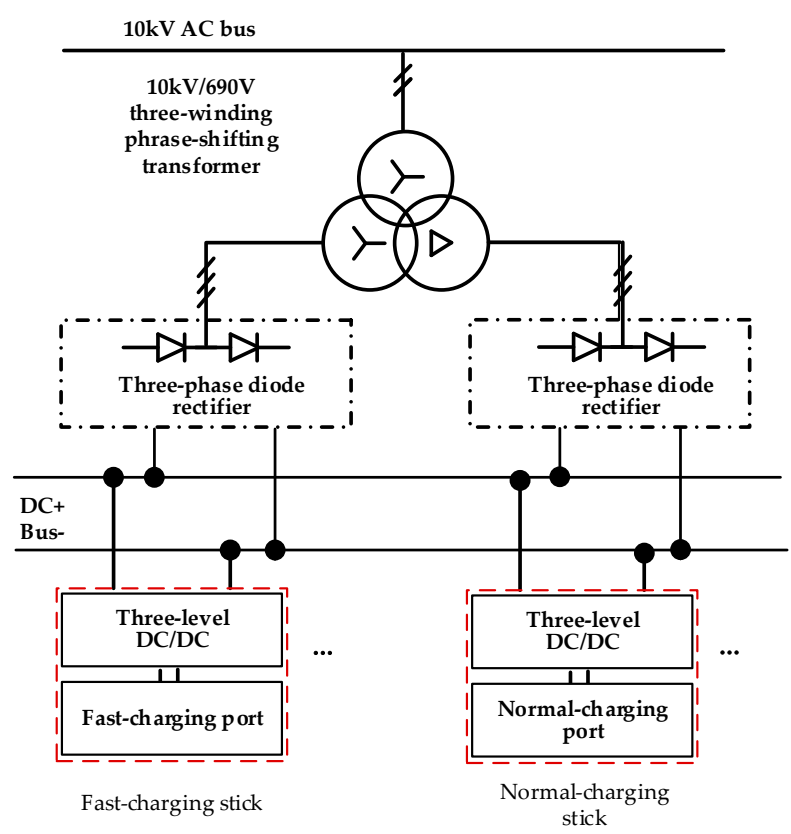

Figure 4. The new charging topology sketch.

\subsection{Charging Schedule Optimization}

At present, the PEB is fully charged for use in the next day when it has finished its last trip back to the station. This may lead to charging congestion and can produce a load peak. Furthermore, the PEBs usually charge during the peak tariffs, so the electricity cost will be high. Therefore, the strategy is to adopt fast-charging during operating time to support the great charging amount, and normal charging at night to reduce the peak load and electricity cost. The normal charging at night is easy to accomplish through an arrangement, considering the number of PEBs, valley tariffs duration, and peak power suppression goal. The peak charging power will not exceed use during the operating hours because of the total electricity demand of the PEBs and the long spare time duration.

Regarding the random charging during operating hours, the fact that the drivers charge randomly and frequently is the main factor leading to a huge peak charging power. According to the operation characteristics of the station and the fleet, the peak charging power can be decreased through the charging sequence and duration optimization of each PEB. The optimization model is as follows:

$$
\operatorname{minimize}\left(\max \sum_{k=1}^{m} P_{c h}^{k}(t)\right), \mathrm{t} \in\left(V_{i, s}^{k}, V_{i, e}^{k}\right), \mathrm{i}=1,2,3 \ldots \mathrm{N}_{B}^{k}
$$


in Equation (2), it is as follows:

$$
\begin{gathered}
V_{i, e}^{k}=V_{i, s}^{k}+a_{i}^{k} \\
a_{i}^{k}=d_{i}^{k} \cdot t_{i}^{k}
\end{gathered}
$$

where $k$ is the PEB number; $m$ is the total quantity of PEBs of the fleet; $t$ is time in minute; $i$ is the sequence of PEB returning to the station; $P_{c h}^{k}(t)$ is the charging power of PEB $k$ on $t$; and $a_{i}^{k}$ is the actual charging duration of PEB $k$ on the $i$ th backing to the station, which belongs to the charging combination matrix.

The constraint conditions are as follows.

(1) Balance of electricity cost of each PEB

Assuming that the charging power of each stick is constant, the daily electricity cost of the PEB can be presented by the charging duration of one day.

$$
\sum_{i=1}^{N_{B}^{k}} a_{i}^{k}=N_{r}^{k} \cdot \beta_{k}, \mathrm{i}=1,2,3 \ldots \mathrm{N}_{B}^{k}
$$

where, $N_{r}^{k}$ is the daily charging number of PEB $k$ in line $r$, which can simplify the charging power and electricity of the model by the charging time. It depends on the line distance, unit energy consumption, and daily running mission of PEB $k . \beta_{k}$ is the charging duration of PEB $k$ of one loop.

(2) One time charging electricity constraint

For the different running loops of each backing station, the electricity quantity charged to the PEB cannot exceed the consumption of the former operation.

$$
\begin{gathered}
E_{i}^{k}=E_{(i-1)}^{k}+a_{i}^{k} \cdot p_{c h} \\
0 \leq E_{i}^{k} \leq E_{0}^{k}
\end{gathered}
$$

(3) Number of the sticks

The synchronous charging service ability is constrained to the number of the sticks, which is the maximum threshold of the charging PEBs at the same time.

$$
\sum_{k=1}^{m} P_{c h}^{k}(t) \leq p_{c h} \cdot \mathrm{N}_{s t i c k}
$$

(4) Evaluation metric

The station electricity cost is set as one economic index in order to evaluate the optimization effect.

$$
\mathrm{C}_{E_{-} \text {total }}=\sum_{t=a}^{b} \sum_{k=1}^{m} P_{c h}^{k}(t) \cdot c_{\text {ele }} \cdot \Delta t
$$

According to the optimal issue's characteristics, the goal is to find solutions that minimize the peak charging power, and the direct result is the bus charging sequence. This is a combinatorial optimization problem that can be solved using the particle swarm optimization (PSO) algorithm. The peak charging power is the algorithm fitness. Depending on the PEBs' charging demand, set the different charging combinations as the particles of the algorithm. Through the algorithm iteration, find the charging schedule corresponding to the minimum peak charging power and its suitable combinations. The effect can be evaluated by the total station electricity cost. 


\section{Configuration of BESS}

As the bus charging station is usually constructed at the start or the end of the bus route, the number of candidate locations are extremely limited, which leads to the distribution capacity becoming the top influential factor. In order to satisfy the grid distribution capacity constraint, the distribution capacity of the charging station may need to be further decreased. Besides the operation optimization, the BESS is a suitably alternative offer. We listed the symbols used in the BESS configuration in Table 5.

Table 5. List of some symbols used in the battery energy storage system (BESS) configuration.

\begin{tabular}{cc}
\hline Symbol & Explanation \\
\hline$x \%$ & Ratio of operation and maintenance cost of the batteries \\
$y \%$ & Ratio of operation and maintenance cost of the converters \\
$C_{\mathrm{E}}$ & Cost of the BESS's unit battery energy \\
$C_{\mathrm{P}}$ & Costs of the BESS's unit converter power \\
$E$ & Rated capacity of BESS \\
$P$ & Rated power of BESS \\
$\gamma$ & Discount rate \\
$P_{B E S S, t}$ & Total charging power of BESS on time $t$ \\
$N_{\text {sum }}$ & Total number of charge-discharge cycle of BESS \\
$S O E_{\min }$ & Minimum state of energy (SOE) of BESS \\
$S O E_{\max }$ & Maximum SOE of BESS \\
$p_{\mathrm{ch}, t}$ & Charging power of BESS on time $t$ \\
$p_{\mathrm{dis}, t}$ & Discharging power of BESS on time $t$ \\
$-P_{\max }$ & Maximum discharging power of BESS \\
$P_{\max }$ & Maximum charging power of BESS \\
$n$ & Number of sample of BESS configuration simulation \\
$T_{n}$ & Sampling period of BESS configuration simulation \\
$Q(n)$ & Energy of BESS at each time of the sample \\
\hline
\end{tabular}

\subsection{Configuration Method}

For the fast-charging stations with the BESS, the investment and profit are affected by the cost of the lithium-ion batteries, converters of the BESS, charging equipment, and purchasing electricity cost. Because of the established charging station, the distribution capacity and the transformer type can be confirmed. The research of this paper only considers the BESS capacity cost and revenue based on the time-of-use electricity price. The compared subjects were two configurations with the original load and optimized load. The economic models of the relevant factors were established as follows.

(1) Full lifetime cost of BESS

$$
\begin{gathered}
W_{t o l}=W_{E}+W_{P} \\
W_{E}=(1+x \%) \cdot C_{E} \cdot E \cdot \frac{\gamma(1+\gamma)^{T}}{(1+\gamma)^{T}-1} \\
W_{P}=(1+y \%) \cdot C_{P} \cdot P \cdot \frac{\gamma(1+\gamma)^{T}}{(1+\gamma)^{T}-1} \\
N_{c h, d a y}=\frac{\sum_{t=1}^{T^{*}} P_{B E S S, t} \times \Delta t}{E},\left(P_{B E S S, t}>0\right) \\
N_{\text {disch,day }}=\frac{\sum_{t=1}^{T^{*}} P_{B E S S, t} \times \Delta t}{E},\left(P_{B E S S, t}<0\right) \\
T=\frac{N_{\text {sum }}}{N_{\text {disch,day }}}
\end{gathered}
$$

where $W_{t o l}$ is the full lifetime cost of BESS, $W_{E}$ and $W_{P}$ are the translated daily costs with the estimated lifetime, which are the BESS battery costs and the connected converter costs in accordance with the 
initial investment. $N_{c h, d a y}$ and $N_{\text {disch,day }}$ are the charging and discharging number of the BESS in each day, respectively, which are also used to calculate the using lifetime of the BESS. $T$ is the estimated lifetime of the BESS.

(2) Electricity cost

$$
W_{\text {ele }}=\sum_{t=1}^{T^{*}} E_{t} \cdot c_{\text {ele }}
$$

where $E_{t}$ is the electricity consumption on time $t$, and $W_{\text {ele }}$ is the electricity cost in the BESS configuration

(3) Objective function of configuration

$$
\operatorname{minimize}\left(W_{E}+W_{P}+W_{\text {ele }}\right)
$$

where $W_{\mathrm{E}}, W_{P}$, and $W_{\text {ele }}$ are all related to $E$, the size of the BESS. $E$ is the main variable of the function.

\subsection{Model Constraints and Optimization Steps}

The configuration object is related to the power balance, the discharging energy, the SOC of the batteries, and the charging-discharging power of the BESS. The details of the constraints are shown as follows:

(1) Power balance constraint

During the station operation process, the BESS charging power is supplied by the grid, while the discharging power of the BESS only supplies the PEBs charging load.

$$
P_{\text {char }, t}=P_{\text {grid }, t}+P_{\mathrm{BESS}, t}
$$

where $P_{\text {grid, } t}$ is the power supplied by the grid in period $t ; P_{\mathrm{BESS}, t}$ is the charging-discharging power of BESS; charging power is + ; discharging power is - ; and $t$ is the period of $[t-1, t]$.

(2) BESS energy constraint

In order to ensure the sustainable operation of the BESS, the charging energy should match the discharging energy at the end of each operation cycle. The peak charging power constraint of the station is a constant condition, which is described in Equation (23).

$$
\sum_{1}^{T^{*}} p_{\mathrm{dis}, t} \Delta t=\sum_{1}^{T^{*}} p_{\mathrm{ch}, t} \cdot \Delta t
$$

(3) BESS SOC constraint

During the BESS operational procedure, the SOC of the BESS should be constrained in a suitable range, called the depth of discharging (DOD), to keep the BESS working well. This also decides the total discharging and charging energy of the BESS. Usually, the SOC range of the BESS is $20 \%$ to $90 \%$, which means the DOD is $80 \%$.

$$
\begin{gathered}
\operatorname{SOE}(t+1)=S O E(t)-\frac{p_{\mathrm{dis}, t} \cdot \Delta t}{\eta_{\mathrm{dis}} \cdot E} \\
S O E(t+1)=S O E(t)+\frac{\eta_{\mathrm{ch}} \cdot p_{\mathrm{ch}, t} \cdot \Delta t}{E} \\
S O E_{\min } \leq S O E(t) \leq S O E_{\max }
\end{gathered}
$$

where $\operatorname{SOE}(t)$ is the state of energy of the battery at $t, \eta_{\text {dis }}$ is the discharge efficiency, and $\eta_{\mathrm{ch}}$ is the charge efficiency. 
(4) BESS power constraint

The maximum charging and discharging power should be set to keep the batteries safe during the operation, which is also related to the energy and power of the BESS.

$$
-P_{\max } \leq P_{\mathrm{BESS}, t} \leq P_{\max }
$$

\subsection{Optimization Steps}

In this paper, the BESS configuration was a single objective optimization issue. The objective function and constraint conditions were also linear, so using Linear Programming to solve this problem was suitable. During the optimization process, the algorithm steps were as follows:

Step 1: Setting $24 \mathrm{~h}$ as the simulation cycle time, the sampling period, $T_{n}$, based on the optimized time interval, which can decide the number of sample, $n$, taking the energy of BESS at each sample time as the variable, $Q(1), Q(2), \ldots, Q(n-1), Q(n)$;

Step 2: Calculating the power of the BESS of each sample spot based on the sample cycle as $[Q(2)-Q(1)] / T_{n},[Q(3)-Q(2)] / T_{n}, \ldots,[Q(n)-Q(n-1)] / T_{n},[Q(1)-Q(n)] / T_{n}$, the positive value means charge, and the negative value means discharge;

Step 3: According to the maximum DOD, calculating the energy and power of BESS, as shown in Equations (24) and (25);

$$
\begin{gathered}
E=\max (Q(1), Q(2), \ldots, Q(n-1), Q(n)) / D O D \\
P=\max \left\{\left|[Q(2)-Q(1)] / T_{n}\right|,\left|[Q(3)-Q(2)] / T_{n}\right|, \ldots,\left|[Q(n)-Q(n-1)] / T_{n}\right|,\left|[Q(1)-Q(n)] / T_{n}\right|\right\}
\end{gathered}
$$

Step 4: According to the charging load of the station, using Linear Programing to solve Equation (17) with Constrains (19)-(23).

\section{Case Study and Results}

\subsection{Charging Schedule Optimization}

The buses were strictly launched according to the operation schedule, and the departure interval varied in different periods and routes. The minimum time interval was $15 \mathrm{~min}$. Through the departure characteristics, energy consumption, and running distance, the maximum running loops under the safety SOC (30\%) threshold can be developed. Using line H55 as an example, the energy consumption per kilometer was $0.854 \mathrm{kWh}$, the loop length was $9 \mathrm{~km}$, and the electricity quantity of on-board battery was $119.62 \mathrm{kWh}$. We could see that it was practicable for a PEB running 10 loops with the on-board battery pack on line H55 from Equation (26). To check whether the residual energy was above the safety threshold, Equation (27) is used.

$$
\begin{gathered}
N_{\text {Mloop_H55 }}=\frac{E_{\text {battery }} \times 70 \%}{E_{\mathrm{cos} t_{-} H 55} \times L_{H 55}} \\
S O C_{H 55}=\frac{E_{\mathrm{cos} t_{-} H 55} \times L_{H 55} \times N_{\text {loop_H55 }}}{E_{\text {battery }}}
\end{gathered}
$$

where $N_{M l o o p}$ is the maximum running loops of one of the PEBs of line H55, $E_{\text {battery }}$ is the electricity of the on-board battery, and $L_{H 55}$ is the length of line H55. $N_{\text {loop_H55 }}$ is the number of decided running loops, and $S O C_{H 55}$ is the energy consumption rate of the on-board battery. All of the results are shown in Table 6. 
Table 6. Suitable loops for each line.

\begin{tabular}{ccccccc}
\hline Line No. & $\begin{array}{c}\text { Goal } \\
\text { Loops }\end{array}$ & $\begin{array}{c}\text { Length } \\
\mathbf{( k m )}\end{array}$ & $\begin{array}{c}\text { Suitable } \\
\text { Loops }\end{array}$ & $\begin{array}{c}\text { Distance } \\
\mathbf{( k m )}\end{array}$ & $\begin{array}{c}\text { Total ele. } \\
\text { Cost (kWh) }\end{array}$ & $\begin{array}{c}\text { SOC Cost } \\
(\mathbf{\%})\end{array}$ \\
\hline H55 & $9(10)$ & 9 & 10 & 90 & 76.86 & 64.25 \\
H56 & 10 & 12 & 7 & 84 & 72.16 & 60.32 \\
863 & 5 & 27 & 3 & 81 & 71.77 & 60.00 \\
864 & $4(5)$ & 36 & 2 & 72 & 69.05 & 57.72 \\
869 & $5(6)$ & 22 & 3 & 66 & 63.03 & 52.69 \\
\hline
\end{tabular}

The fast-charging of PEBs usually uses the constant current stage. In order to simplify for calculation, the monthly mean charging power is used as the nominal optimal charging power. The whole charging electricity of one month was $157,501.8 \mathrm{kWh}$, the charging duration was 41,382 min, and the mean charging power was $228.36 \mathrm{~kW}$ from Equation (28), setting $228 \mathrm{~kW}$ as the calculation value to ensure a complete charging.

$$
P_{\text {ave }}=\frac{E_{\text {month }}}{T_{\text {month }}} \times 60
$$

where $P_{\text {ave }}$ is the average charging power, and $E_{\text {month }}$ and $T_{\text {month }}$ are the monthly electricity and charging duration, respectively.

Through the optimization, the charging schedule was obtained, as shown in Table 7. The letters A to $G$ are the labels of the buses on different bus lines, and the numbers in the crossing of the row and column are the charging orders when PEBs return to the station.

Table 7. Optimized charging schedule for each route.

\begin{tabular}{cccccccc}
\hline Line No./Bus Label & $\mathbf{A}^{\mathbf{1}}$ & B & C & D & E & F & G \\
\hline H55 & 7 & 7 & 7 & 7 & 7 & - & - \\
H56 & 6 & 6 & 6 & 6 & 6 & - & - \\
863 Up & $1,3^{2}$ & 1,3 & 1,3 & 1,3 & 2,3 & 1,3 & 1,3 \\
863 Down & 1,3 & 2,3 & 2,3 & 2,3 & 1,3 & 1,3 & 1,3 \\
864 & 1,2 & 1,2 & 1,2 & 2,3 & 2,3 & 1,2 & 1,2 \\
869 Up & 1,2 & 1,2 & 2,4 & 1,2 & 1,2 & 3,4 & 1,2 \\
869 Down & 1,2 & 1,2 & 3,4 & 1,2 & 1,2 & 3,4 & 1,2 \\
\hline
\end{tabular}

1 The label of PEB in each line, e.g., H55-A, H55-B . . , H56-E. ${ }^{2}$ The PEB 863 Up-A should charge on the first and third returns to the station.

According to the optimized charging sequence, the corresponding charging durations will be decided. The obtained optimized charging load is shown in Figure 5, where the peak charging power was significantly decreased at only $912 \mathrm{~kW}$. As the simulation charging power of the stick was $228 \mathrm{~kW}$, the number of sticks charging synchronously was four, which was obviously reduced when compared with the original seven sticks. This means that the investment may be cut in half by the charging sequence optimization. 


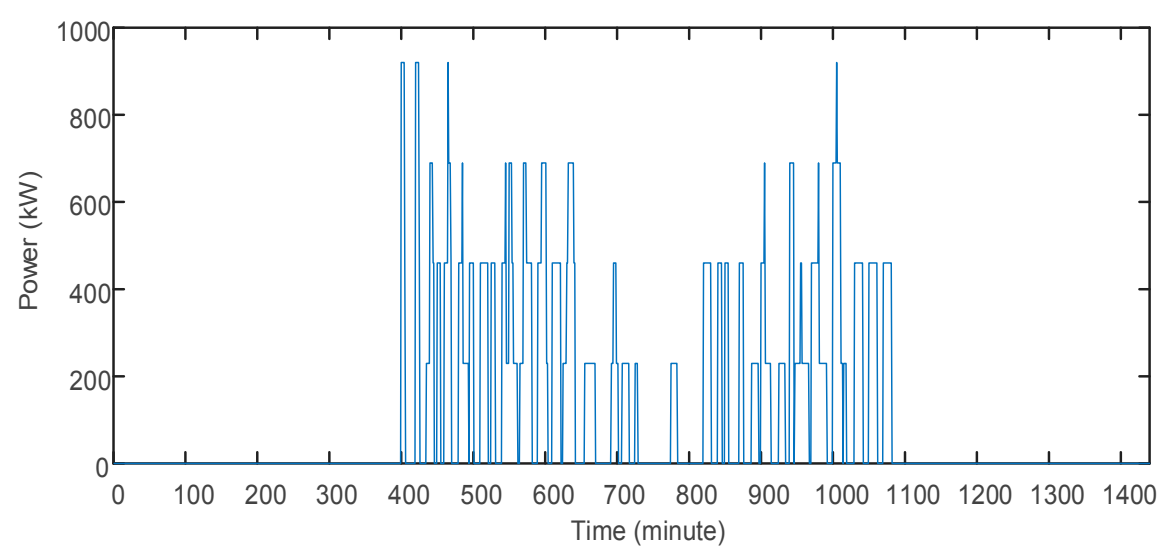

Figure 5. Optimized charging load in operating time.

The purchasing electricity fee is shown in Table 8. This mode could shift the daytime load to the night and made good use of the TOU electricity prices as shown in Table 9. The electricity cost saved was $1544.7 \mathrm{CNY}(37.1 \%)$. Furthermore, the peak charging power declined from $1601.7 \mathrm{~kW}$ to $912 \mathrm{~kW}$, a reduction of $690 \mathrm{~kW}(43.07 \%)$. The basic capacity cost of the transformer can be reduced by about $736 \mathrm{CNY} /$ day when compared to the original peak charging power. The total cost saved was up to $2280.7 \mathrm{CNY} /$ day.

Table 8. The cost of different charging modes.

\begin{tabular}{ccccc}
\hline $\begin{array}{c}\text { Daytime Elec. } \\
(\mathbf{k W h})\end{array}$ & $\begin{array}{c}\text { Night Elec. } \\
\mathbf{( k W h )}\end{array}$ & $\begin{array}{c}\text { Electricity } \\
\text { Price }\end{array}$ & $\begin{array}{c}\text { Peak Power } \\
\mathbf{( k W )}\end{array}$ & $\begin{array}{c}\text { Elec. Fee } \\
\text { (CNY/day) }\end{array}$ \\
\hline 5128.8 & 0 & TOU & 1601.7 & 4163.0 \\
2344.6 & 2784.2 & TOU & 912.0 & 2618.3 \\
\hline
\end{tabular}

Table 9. Time-of-use (TOU) electricity price.

\begin{tabular}{ccc}
\hline Period & Time & Price (CNY/kWh) \\
\hline Village & $23: 00-7: 00$ & 0.3946 \\
Flat & $7: 00-10: 00 ; 15: 00-18: 00$ & 0.6950 \\
Peak & 21:00-23:00 & 1.0044 \\
\hline
\end{tabular}

\subsection{BESS Configuration Case}

According to the configuration presented previously, the schematic figure of the BESS configuration is shown in Figure 6, and the parameters of the model established for BESS configuration in the case study are listed in Table 10. The reason Equation (17) does not include the distribution network basic capacity cost is that the cost is a constant parameter for the case. The simulation is presented in the next section. 


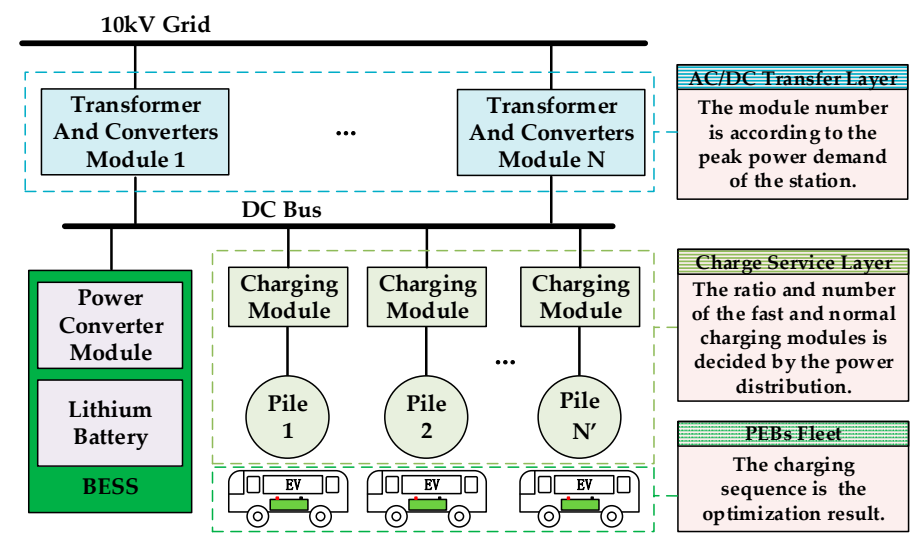

Figure 6. Schematic figure of the battery energy storage system (BESS) configuration.

Table 10. Parameters of the case. SOC—-state of charge.

\begin{tabular}{cc}
\hline Parameter & Value \\
\hline Basic capacity cost of the transformer & 32 \\
$(\mathrm{CNY} /(\mathrm{kVA} \cdot \mathrm{month}))$ & 1500 \\
Battery cost (CNY/kWh) & 500 \\
Converter cost (CNY/kW) & 8 \\
BESS lifetime (Year) & 3 \\
Discount rate $(\%)$ & $20-90$ \\
SOC range of the BESS $(\%)$ & 95 \\
\hline
\end{tabular}

\subsection{Results and Analysis}

As shown in Figure 7, the peak charging power was further reduced. Furthermore, the output power of the BESS was obviously decreased with the optimized charging load. In Figure 6a, the quantity of charging equipment was extremely reduced through the fast-charging mode during the operating hours and the normal charging at night, from seven sticks to four sticks, and the peak charging power was $912 \mathrm{~kW}$. The difference of the optimization compared to the original charging load will be compared in the next section. In the case combined with the configuration of the BESS, the amount of charging sticks working synchronously was reduced to three, and the peak charging power decreased to $684 \mathrm{~kW}$. The charging and discharging power of the BESS were lower with the optimized charging load. Therefore, the energy cost of the electrical energy conversion will be reduced.

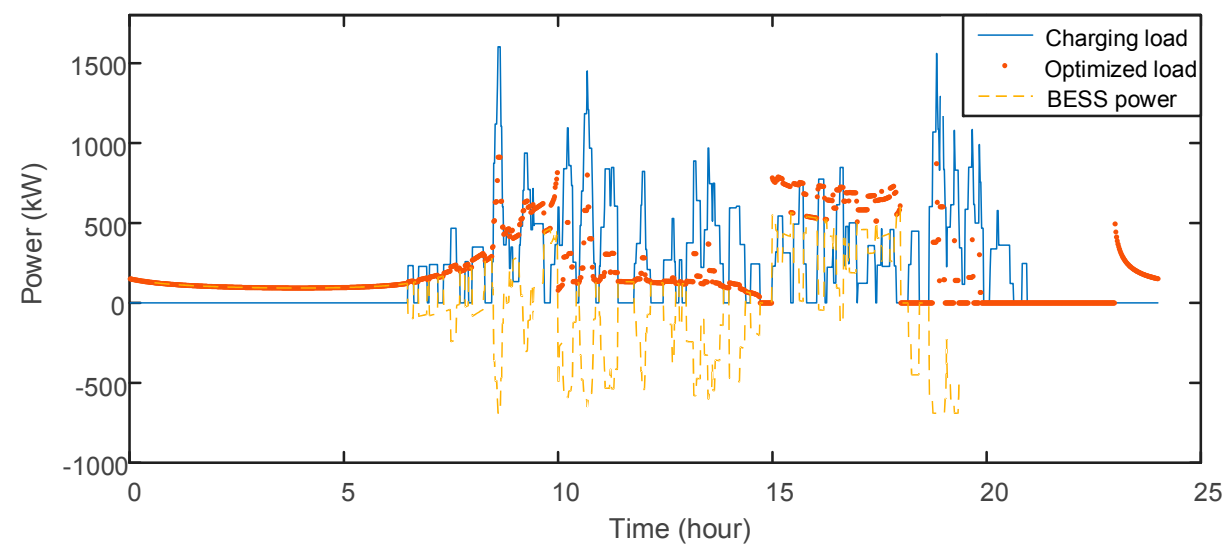

(a)

Figure 7. Cont. 


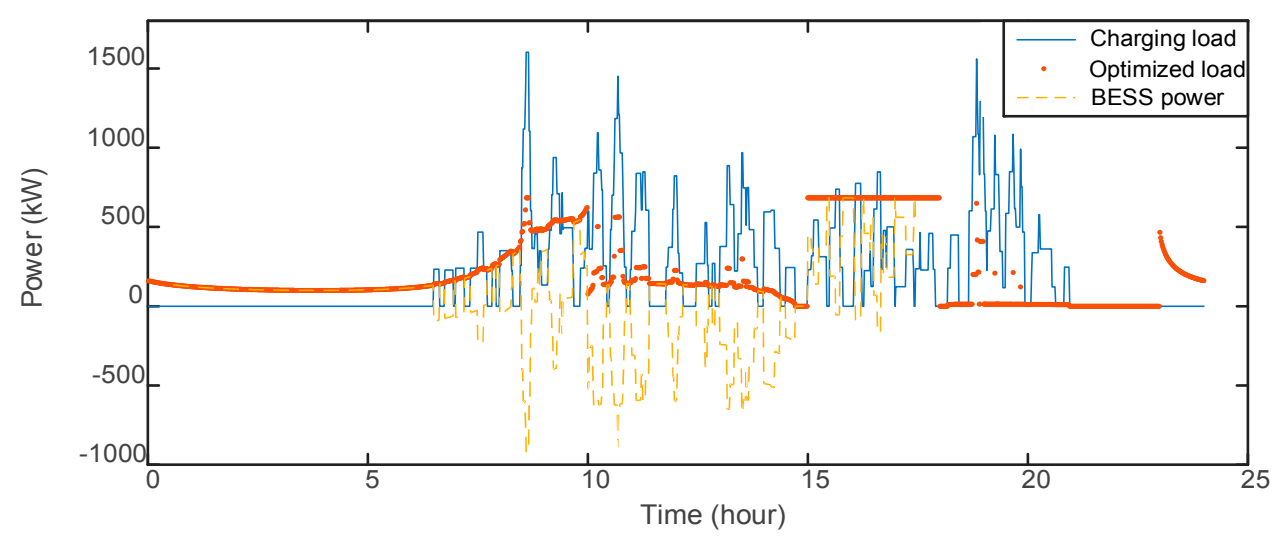

(b)

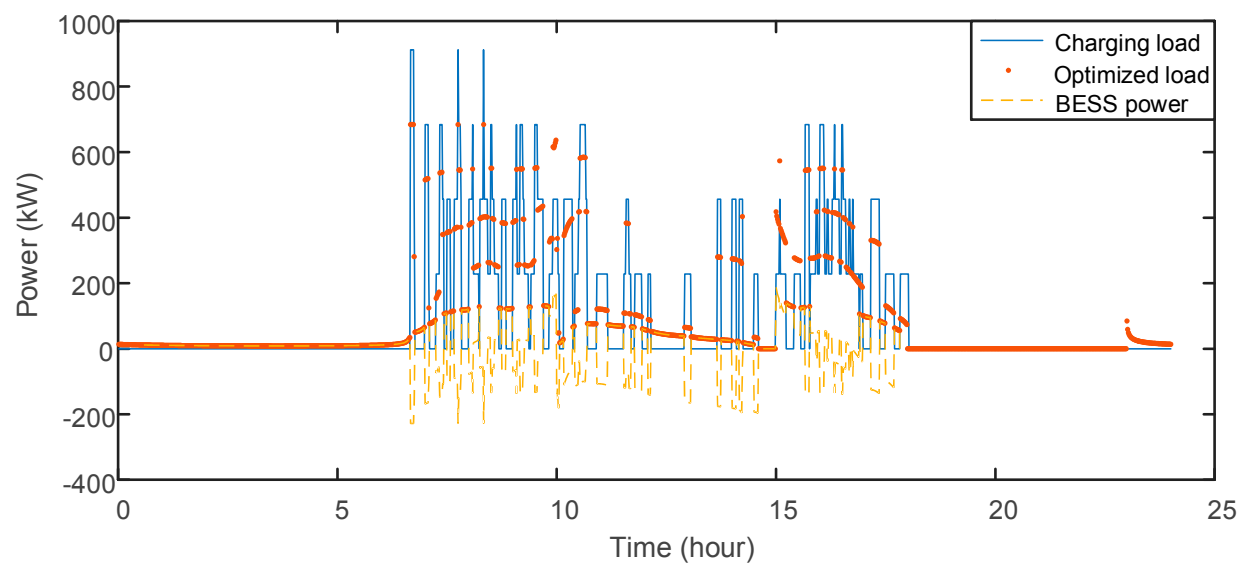

(c)

Figure 7. Charging load and discharging power of BESS. (a) The output power of BESS with the original charging load decreased to $912 \mathrm{~kW}$; (b) the output power of BESS with the original charging load decreased to $684 \mathrm{~kW}$, and (c) the output power of BESS with the optimized charging load decreased to $684 \mathrm{~kW}$.

As shown in Table 11, the total cost including the costs (converted to each single day) of the batteries and converters, was significantly decreased. In particular, the cost of the optimized charging load with the configuration of BESS was the lowest. The original charging load using BESS to shave the peak load could reduce the electricity cost, but the energy capacity of BESS was more than one megawatt. The investment may be more than 2.5 million CNY. According to the peak charging power goal, the investment of BESS may be higher. Configure 1 and Configure 2 separately summarize the costs of the BESS configuration with original charging load when the peak charging power is reduced to $912 \mathrm{~kW}$ and $684 \mathrm{~kW}$. Configure 3 shows the costs of the BESS configuration with an optimized charging load and the goal of the peak charging power $684 \mathrm{~kW}$. Note that the revenue was very little if the BESS was directly used to regulate the original charging load without a basic capacity price. The charging optimization could decrease the peak charging power the most effectively, which also assists in achieving the greatest benefits from the TOU tariffs and a lower BESS investment for the PEB fast-charging station. 
Table 11. Different charging modes' costs with BESS from TOU tariffs.

\begin{tabular}{|c|c|c|c|c|c|}
\hline Parameter & $\begin{array}{l}\text { Original } \\
\text { Load }\end{array}$ & $\begin{array}{c}\text { Configure } \\
1\end{array}$ & $\begin{array}{c}\text { Configure } \\
2\end{array}$ & $\begin{array}{l}\text { Optimized } \\
\text { Load }\end{array}$ & $\begin{array}{c}\text { Configure } \\
3\end{array}$ \\
\hline Daytime energy (kWh) & 5128.8 & 5128.8 & 5128.8 & 2344.6 & 2344.6 \\
\hline Night energy (kWh) & 0 & 0 & 0 & 2784.2 & 2784.2 \\
\hline peak power $(\mathrm{kW})$ & 1601.7 & 912.0 & 684.0 & 912.0 & 684.0 \\
\hline BESS battery (kWh) & 0 & 1292.9 & 1369.5 & 0 & 114.0 \\
\hline Battery cost (CNY / day) & 0 & 757.0 & 801.8 & 0 & 66.8 \\
\hline Converter cost (CNY / day) & 0 & 134.6 & 179.1 & 0 & 44.5 \\
\hline Dischar. Power (kW) & 0 & 689.8 & 917.8 & 0 & 228.0 \\
\hline Electricity fee (CNY) & 4163.0 & 3212.2 & 3155.9 & 2618.3 & 2560.3 \\
\hline Basic Capacity save (CNY/day) & 0 & 736.0 & 979.2 & 736.0 & 979.2 \\
\hline Cost without BCP save (CNY/day) & 4163.0 & 4036.6 & 4252.8 & 2618.3 & 2832.8 \\
\hline Cost with $\mathrm{BCP}$ save (CNY/day) & 4163.0 & 3367.8 & 3157.6 & 1882.3 & 1692.4 \\
\hline
\end{tabular}

\section{Conclusions}

This paper presented the characteristics of the configuration and operation of a PEB fast-charging station in Beijing through real data analysis. A new charging mode of fast-charging during operating hours and normal charging at night for the PEB fast-charging station was proposed. This could effectively reduce the distribution capacity demand of fast-charging stations and decrease the purchasing electricity costs with time-of-use tariffs. A new charging topology was recommended, where it was energy efficient and easy to change the charging power and connect the DC/DC charging modules. The charging sequence for all of the PEBs in the fleet has been optimized. The configuration of BESS, considering the cycle lifetime of the battery was developed to further decline the peak charging power. Linear Programing was used to solve the BESS configuration. Cases of BESS configuration with the original and optimized charging load were presented, and the results of the cases were compared. A two-step optimization strategy was effective for the peak charging power suppression. For the distribution capacity demand restraint of the fast-charging station at different power levels, this research can be a reference for the design procedure.

Author Contributions: Y.Y. proposed the charging optimization model and strategy, and wrote the paper; H.W. performed the BESS configuration simulations; Y.Y., W.Z., M.H., and Q.C. analyzed the results; and J.J. organized the structure of the paper.

Funding: This research received no external funding.

Acknowledgments: This work was supported by the National Key R\&D Program of China (2016YFB0900505).

Conflicts of Interest: The authors declare no conflict of interest.

\section{References}

1. Geng, B.; Mills, J.K.; Sun, D. Two-Stage Charging Strategy for Plug-In Electric Vehicles at the Residential Transformer Level. IEEE Trans. Smart Grid 2013, 4, 1442-1452. [CrossRef]

2. Hajforoosh, S.; Masoum, M.A.S.; Islam, S.M. Real-time charging coordination of plug-in electric vehicles based on hybrid fuzzy discrete particle swarm optimization. Electr. Power Syst. Res. 2015, 128, 19-29. [CrossRef]

3. Sundstrom, O.; Binding, C. Flexible Charging Optimization for Electric Vehicles Considering Distribution Grid Constraints. IEEE Trans. Smart Grid 2012, 3, 26-37. [CrossRef]

4. Mahmoud, M.; Garnett, R.; Ferguson, M.; Kanaroglou, P. Electric buses: A review of alternative powertrains. Renew. Sustain. Energy Rev. 2016, 62, 673-684. [CrossRef]

5. Meintz, A.; Zhang, J.; Vijayagopal, R.; Kreutzer, C.; Ahmed, S.; Bloom, I.; Burnham, A.; Carlson, R.B.; Dias, F.; Dufek, E.J.; et al. Enabling fast charging_Vehicle considerations. J. Power Sources 2017, 367, 216-227. [CrossRef]

6. Serradilla, J.; Wardle, J.; Blythe, P.; Gibbon, J. An evidence-based approach for investment in rapid-charging infrastructure. Energy Policy 2017, 106, 514-524. [CrossRef]

7. Xylia, M.; Leduc, S.; Patrizio, P.; Kraxner, F.; Silveira, S. Locating charging infrastructure for electric buses in Stockholm. Transp. Res. Part C Emerg. Technol. 2017, 78, 183-200. [CrossRef] 
8. Bao, Y.; Luo, Y.; Zhang, W.; Huang, M.; Wang, L.; Jiang, J. A Bi-Level Optimization Approach to Charging Load Regulation of Electric Vehicle Fast Charging Stations Based on a Battery Energy Storage System. Energies 2018, 11, 229. [CrossRef]

9. Bryden, T.S.; Hilton, G.; Cruden, A.; Holton, T. Electric vehicle fast charging station usage and power requirements. Energy 2018, 152, 322-332. [CrossRef]

10. Leou, R.; Hung, J. Optimal Charging Schedule Planning and Economic Analysis for Electric Bus Charging Stations. Energies 2017, 10, 483. [CrossRef]

11. Qin, N.; Gusrialdi, A.; Paul Brooker, R.; T-Raissi, A. Numerical analysis of electric bus fast charging strategies for demand charge reduction. Transp. Res. Part A Policy Pract. 2016, 94, 386-396. [CrossRef]

12. Wu, D.; Aliprantis, D.C.; Ying, L. Load Scheduling and Dispatch for Aggregators of Plug-In Electric Vehicles. IEEE Trans. Smart Grid 2012, 3, 368-376. [CrossRef]

13. Khan, S.; Mehmood, K.; Haider, Z.; Bukhari, S.; Lee, S.; Rafique, M.; Kim, C. Energy Management Scheme for an EV Smart Charger V2G/G2V Application with an EV Power Allocation Technique and Voltage Regulation. Appl. Sci. 2018, 8, 648. [CrossRef]

14. Mao, T.; Zhang, X.; Zhou, B. Modeling and Solving Method for Supporting 'Vehicle-to-Anything' EV Charging Mode. Appl. Sci. 2018, 8, 1048. [CrossRef]

15. Gan, L.; Topcu, U.; Low, S.H. Optimal decentralized protocol for electric vehicle charging. IEEE Trans. Power Syst. 2013, 28, 940-951. [CrossRef]

16. Yang, Y.; Zhang, W.; Niu, L.; Jiang, J. Coordinated charging strategy for electric taxis in temporal and spatial scale. Energies 2015, 8, 1256-1272. [CrossRef]

17. Chen, H.; Hu, Z.; Xu, Z.; Li, J.; Zhang, H.; Xia, X.; Ning, K.; Peng, M. Coordinated charging strategies for electric bus fast charging stations. In Proceedings of the IEEE PES Asia-Pacific Power and Energy Conference, Xian, China, 25-28 October 2016; pp. 1174-1179.

18. Zhang, K.; Xu, L.; Ouyang, M.; Wang, H.; Lu, L.; Li, J.; Li, Z. Optimal decentralized valley-filling charging strategy for electric vehicles. Energy Convers. Manag. 2014, 78, 537-550. [CrossRef]

19. Rivera, S.; Wu, B.; Kouro, S.; Yaramasu, V.; Wang, J. Electric Vehicle Charging Station Using a Neutral Point Clamped Converter With Bipolar DC Bus. IEEE Trans. Ind. Electron. 2015, 62, 1999-2009. [CrossRef]

20. Grackova, L.; Oleinikova, I. Impact of Electric Vehicle Charging on the Urban Distribution Network. In Proceedings of the 57th International Scientific Conference on Power and Electrical Engineering of Riga Technical University (RTUCON), Riga, Latvia, 13-14 October 2016.

21. Makohin, D.; Jordan, F.V.; Zeni, V.S.; Lemos, K.H.M.; Pica, C.; Gianesini, M.A. Use of Lithium Iron Phosphate Energy Storage System for EV Charging Station Demand Side Management. In Proceedings of the IEEE International Symposium on Power Electronics for Distributed Generation Systems, Florianópolis, Brazil, 17-20 April 2017; pp. 1-6.

22. Negarestani, S.; Fotuhi-Firuzabad, M.; Rastegar, M.; Rajabi-Ghahnavieh, A. Optimal Sizing of Storage System in a Fast Charging Station for Plug-in Hybrid Electric Vehicles. IEEE Trans. Transp. Electr. 2016, 2, 443-453. [CrossRef]

23. Dean, D.; Ortmeyer, T.; Wu, L. Transportation modeling and data needs for fast charging electric vehicles. In Proceedings of the 2016 International Conference on Electrical Systems for Aircraft, Railway, Ship Propulsion and Road Vehicles and the International Transportation Electrification Conference (ESARS-ITEC), Toulouse, France, 2-4 November 2016; pp. 1-6.

(C) 2018 by the authors. Licensee MDPI, Basel, Switzerland. This article is an open access article distributed under the terms and conditions of the Creative Commons Attribution (CC BY) license (http://creativecommons.org/licenses/by/4.0/). 